\title{
A Numerical Investigation of Emissions Generated by Alternative Aircraft Fuels Using Spice Transport Approach
}

\author{
Iho López Tobi
}

University of Salford, Manchester,UK

* Correspondence: iholoipeztobi@gmail.com

\begin{abstract}
The present is a study of the CFD simulations intended to simulate the emissions of pollutants that are generated after the combustion of proposed alternative aircraft fuels (Hydrogen, Ethanol and Methane) to compare with the emissions generated after the combustion of Kerosene and Benzene in a 2D cylindrical combustion chamber. Given that air traffic is a main contributor to not only $3 \%$ of man-made greenhouse effects but also of the generation of smog over heavy air traffic urban areas generating an impact on the air quality and the population of those areas.
\end{abstract}

Keywords: Hydrogen Combustion; Alternative Fuels; NOX Emissions

\section{Introduction}

Before the start of the pandemic caused by Covid-19 aviation was considered one of the fastest growing industries in the world. At the start of the pandemic and during its most critical times, during the lockdown experienced in Spain starting march 14th 2020 ending in June 21st 2020 this sector experienced a $70 \%$ reduction of operations in the country alone, to further have domestic flights come to a halt. Aviation is one of the fastest energy consumer sectors increasing its fuel demand progressively at the same time that contributes to $3 \%$ of greenhouse gasses and smog formation.[2] In the article Lessons from the COVID-19 air pollution decrease in Spain: Now what?, written by Xavier Querol Jordi Massagué Andrés Alastuey Teresa Moreno, et al. It presents factual data stating that during the months of lockdown in Spain, traffic flow decreased up to $80 \%$ where NO2 levels fell below $50 \%$, reinforcing the statement of how prominent NOx emissions are in urban areas contributing to the decay of air quality as per figure (1) that demonstrates the smog formation over the city of Barcelona on February Thursday 3rd 2022 at $11 \mathrm{am}$. One of the issues is that the preferred fuels used by humans given their ability to provide great amounts of energy output, as well as their performance, handling experience and availability are petroleum based products that produce elevated amounts of harmful emissions. [13-4-5-8] 


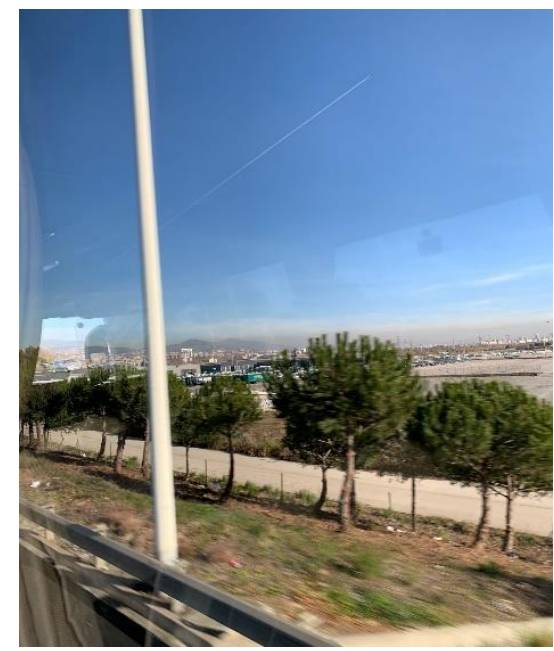

Figure 1. Smog formation over the city of Barcelona, Spain taken February 3rd, 2022

The non-deniable contribution of greenhouse gasses and emissions on global warming coupled with the need of finding green sources of fuel given that petroleum is finite and the utter need for better life quality has to be taken into consideration in order to start a transition to cleaner energy. By proposing the introduction of alternative fuels it is important to have in consideration the emissions and their impact on the environment to ensure that progress to a greener and more sustainable society is being made. There is potential for the creation of aircrafts powered by alternatives to non conventional fuels but it is important that these operate with less natural resources and have a much smaller impact on the environment at the same time that are capable of performing the same missions as current aircrafts. [3-9]

There have been numerous steps taken into the direction of reducing aircraft emissions such as the implementation of winglets that allow in the reduction of drag increasing fuel efficiency since less fuel is consumed less emissions are generated. In addition to this concept, there are new ideas being proposed to achieve flight efficiency in terms of fuel consumption such as the concept of blended wing bodies that airbus together with the university of TU Delft is working towards the implementation of, expected to reduce fuel consumption and thus reduce emissions, aside from other concept aircraft that Airbus is working on. [6]

In the article Hydrogen as aviation fuel: A comparison with hydrocarbon fuels written by A. Contreras, * , S. Yiğitt, K. Özayt, T.N. Veziroğlut, (1997) it is proposed hydrogen, as the alternative fuel source to replace fossil fuels in air transportation. It states that Hydrogen has unique attributes beneficial to not only the environment but also for safety purposes such as availability, safety, minimum pollution and light weight, making it an ideal fuel.

For instance in the article Hydrogen or methanol in the transportation sector written by C. Azar, K. Lindgren, Björn A. Andersson, hydrogen and methanol are proposed as alternative energies for aircraft fuels, where they state that methanol, like gasoline, is a liquid fuel at normal temperature and pressure which facilitates transportation and refueling. Further stating that its distribution will resemble that of gasoline, with the main difference that the energy density of methanol is lower hence expecting that its cost of distribution will be higher. In contrast hydrogen is a gas at normal temperature and pressure hence its distribution and refueling will become more complicated. 
The proposed fuels to be studied are Hydrogen, ethanol and methane as alternatives to Kerosene and Benzene. These are important since the emissions impacting and diminishing air quality generated after the combustion of fuel in current aircraft turbines are carbon dioxide (CO2), hydrocarbons that are left unburned (UHC), carbon monoxide (CO) and NOx, ultimately contributing to global warming. Nitrogen dioxide is an irritant gas that can cause irritation to the respiratory paths. When nitrogen is released during the combustion of fuel it blends with oxygen atoms to produce nitric oxide. Nitric oxide further combines with oxygen to produce nitrogen dioxide, which can be hazardous to health in typical ambient conditions. NOx gasses form smog and acid rain as well as being key formators of fine particles and ground level ozone both attributed to produce adverse health effects.[7-9-11-18]

The different phases of an aircraft mission are going to be divided in two stages labeled as ground stage, the actions an aircraft takes while remaining in a non flight stage with the engines turned on, and flight stage, the operations an aircraft takes while being airborne or beginning to be. The ground stages are the taxing, idle and maneuvering to position the aircraft to take off. The flight stages are the take off, climb, cruise and approaching where landing ultimately occurs. At the ground stage the emissions more concerning and that have to be reduced are the hydrocarbons left unburned, while in the flight stage the emissions that are to be more concerned with are NOx. The concerns moving to make an introduction of alternative fuels is firstly the diminishing of air quality over and near urban areas located near high concentration of air traffic, meanwhile the second concern is the generation of greenhouse gasses that affect the ozone layer. Given the context of greenhouse gasses, and emissions generated by civil aircrafts near urban areas, this paper is going to simulate the combustion and the emission of pollutants of the alternative fuels generated by a civil aircraft combustor. For this study we are going to solely display results for the take off phase as this is the most critical phase in terms of fuel energy, burning ratio. [27-24]

\section{Materials and Methods}

In this paper there are discussed the behaviors of the alternative fuels as proposed suitors for commercial operation and compare its emissions to kerosene and benzene. For the present study a 2D geometry was used to simulate the combustor where the combustion took place to further analyze the emissions produced by these. The model is designed and analyzed using Fluent.

\section{Geometry}

The creation of the geometry for the 2D cylinder combustor has been carried out via ansys designmodeler. The numerical simulation takes place in a 2D cylindrical combustion chamber with height $0.255 \mathrm{~m}$ and length $1.8 \mathrm{~m}$ as shown in figure 2 . 


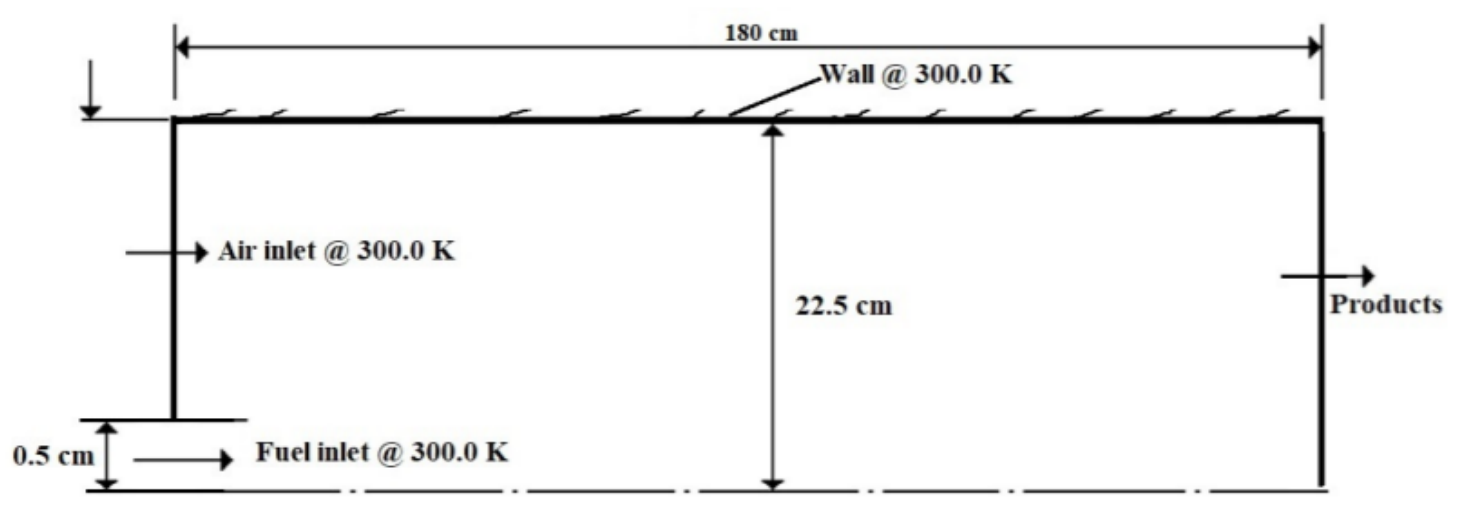

Figure 2. Combustion chamber

\section{Mesh}

The mesh generation was performed using Ansys fluent mesh. The obtained mesh has 4489 nodes and 4256 elements. The chosen mesh is a Quadrilateral structured in both faces where clustering takes place near the wall.

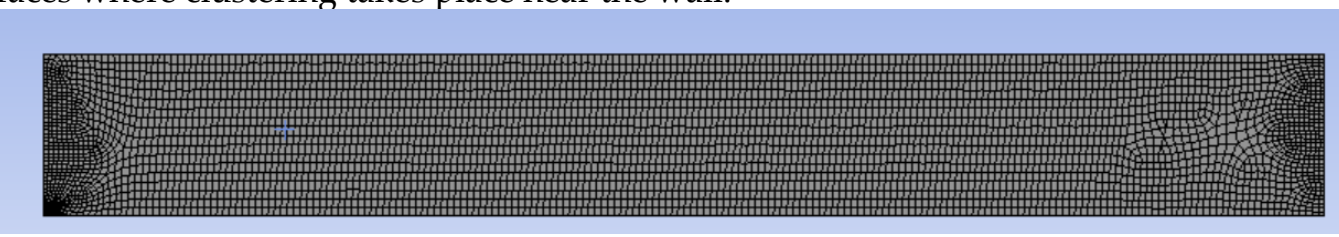

\section{Figure 3. Combustion chamber mesh}

For the simulations carried out in the study, the energy model was enabled, this model must be activated due to the energy produced by the temperature changes within the combustion process. For the turbulence model a k-epsilon standart two equations turbulence model was selected. As per the combustion simulation a spice transport approach was taken to carry out the study, where it can be analyzed the area average velocity and average temperature, as well as spice's mass fractions. Enabling the NOX model emissions it can be displayed information regarding its formation inside the combustion chamber. The walls of the combustor were set to no slip condition. The boundary conditions of the simulation are as stated in table 1.

Table 1. Boundary conditions for the simulation

\begin{tabular}{|l|l|}
\hline Wall Temperature & $300 \mathrm{~K}$ \\
\hline Air inlet $(\mathrm{m} / \mathrm{s})$ & $0,5 \mathrm{~m} / \mathrm{s}$ \\
\hline Fuel inlet $(\mathrm{m} / \mathrm{s})$ & $80 \mathrm{~m} / \mathrm{s}$ \\
\hline Inlet Temperature & Air: $300 \mathrm{~K}$ Fuel: $300 \mathrm{~K}$ \\
\hline Outlet pressure & $0 \mathrm{~Pa}$ \\
\hline Temperature & $300 \mathrm{~K}$ \\
\hline Turbulent intensity & $10 \%$ \\
\hline
\end{tabular}




\section{Results}

\section{Temperature distribution inside combustion chamber}

Present are the temperature contours for hydrogen, ethanol, methane, kerosene, and benzene determined by species transport model Figure (4). It was determined that the highest temperature recorded was produced by hydrogen in comparison to the other tested fuels while kerosene alternative fuel showed lower combustion temperature due to effects of oxygen contents [11]

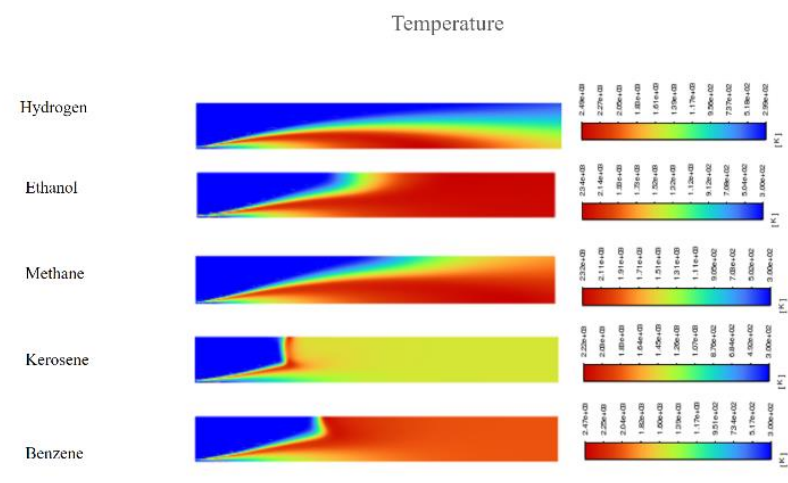

(a)

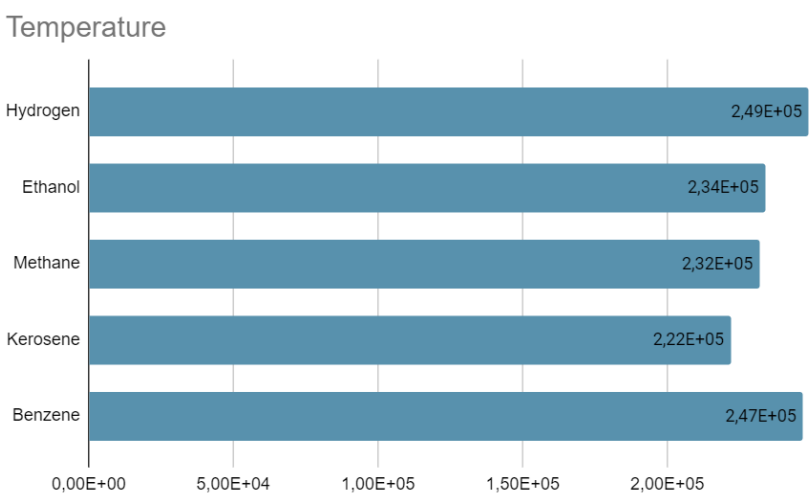

(b)

Figure 4. (a)Temperature contours for combustion chamber. (b) Maximum temperatures recorded for all fuels

\subsection{NOx Pollutants Distribution in the Combustion Chamber}

The formation of NOx during the combustion processes is described by three major formation mechanisms: thermal NOx, fuel NOx and prompt NOx ([16]). Fuel NOx is formed from the nitrogen present in fuel itself. While prompt NOx are the oxides formed quickly through the interaction between oxygen and nitrogen with active hydrocarbon species present. In this section are presented the results of the formation of NOx particles after the combustion has taken place for hydrogen, kerosene, ethanol, methane and benzene in Figure (5). There is a notable temperature dependency in the formation of NOx during the combustion process; higher combustion temperature leads to higher NOX emissions. It is noticed that the proposed alternative fuels have higher 
mass fraction of NO formation during the combustion process, this is due to the noticeable temperature difference among those fuels shown in the previous section, that cause a higher NOx emission directly correlated to the high temperatures reached during the combustion, hence denoting that the increase of NOx emissions during the combustion process is due to the increase of after burn temperatures. [23-10][1-7-19].

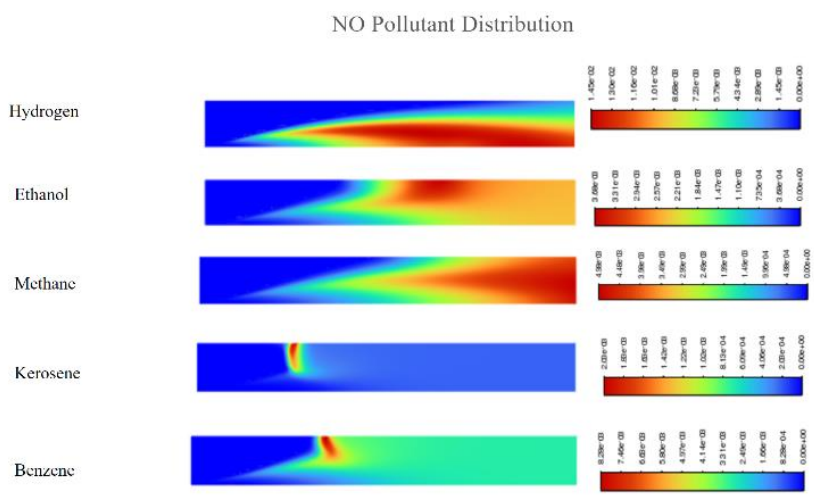

(a)

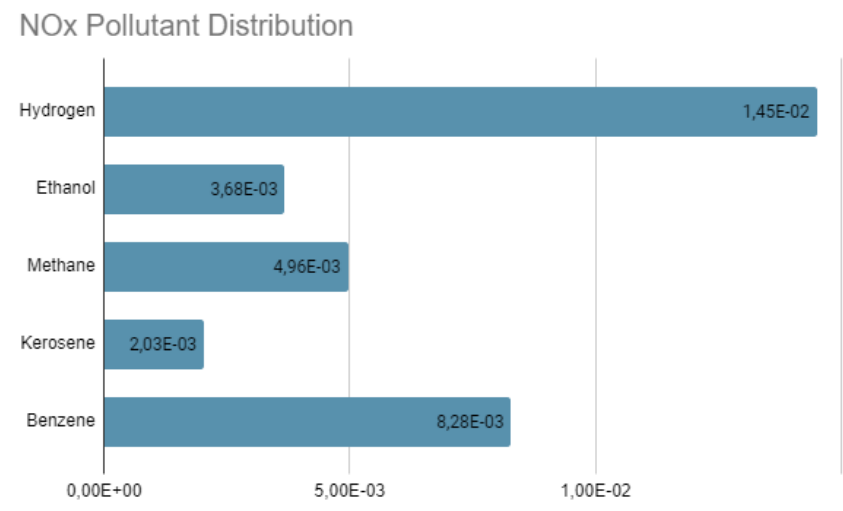

(b)

Figure 5. (a) NO pollutant distribution contours for combustion chamber. (b)Maximum pollutant distribution recorded for all fuels

\subsection{Mass fraction of $\mathrm{CO} 2$ emission}

Carbon dioxide is labeled as a main greenhouse gas, this gas plays a primary role in Earth's global warming [9]. The results demonstrate that great amounts of $\mathrm{CO} 2$ were produced after the combustion in relation to the other pollutants presented in this study, this is expected due to $\mathrm{CO} 2$ and $\mathrm{H} 2 \mathrm{O}$ being a great part of exhaust gasses. It has to be noted that $\mathrm{CO} 2$ emissions tend to increase in the presence of elevated temperatures as we can visualize in the case of benzine where the temperature profile was high and subsequently the CO2 emissions are recorded to be the highest among the fuels tested. This however does not apply to hydrogen [31-33]. It is noted that the formation of CO2 was greatly noticeable for fuels benzene and kerosene this placing second. These are the current fuels being used in aviation and that thus have to be replaced for the harmful emissions they emit, having a stance with hydrogen as this fuel produces no amounts of CO2 
emissions. Here the main hypothesis stands where the alternative fuels to kerosene and benzene are less harmful to the environment as per the contours show as these produce less emissions. It has to be noted that $\mathrm{CO} 2$ emissions depend on viscosity and atomization processes, among other factors. [20-21].

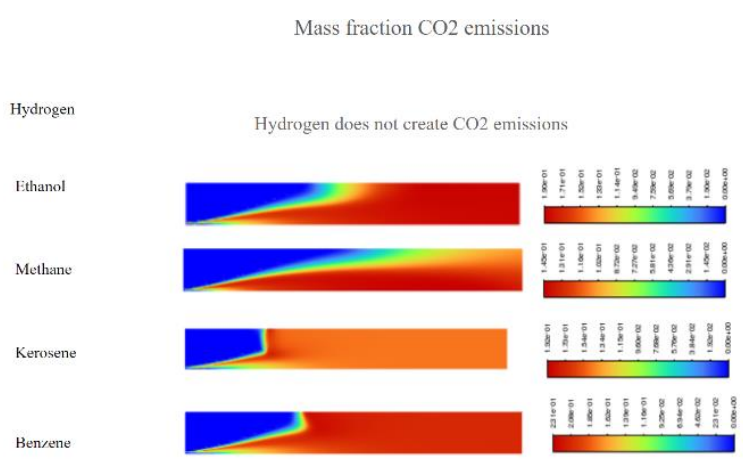

(a)

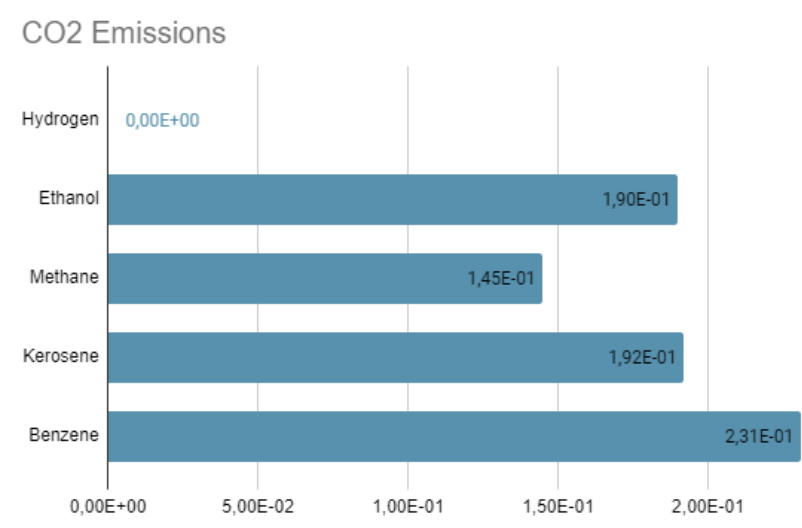

(b)

Figure 6. (a) CO2 Mass Fraction distribution contours for combustion chamber. (b)Maximum $\mathrm{CO} 2$ distribution emissions recorded for all fuels

\subsection{Mass fraction of $\mathrm{O} 2$ pollutant}

In this section we can visualize the contours for $\mathrm{O} 2$ pollutants after the combustion has taken place, we can appreciate from Figure 7 (b) that all fuels produce the same number of maximum mass fraction of $\mathrm{O} 2$ standing at $2.30 \mathrm{E}+01$. The distribution of the contours on figure 7 (a) resemble the inverse of their respective temperature profiles as they share the same flame profile in terms of shape with the contours inverted in colors, we can perceive that oxygen is consumed at the zones of combustion evident from the green color the contours display that represent the low values of mass fraction in those specific areas. The inlet shows the highest formation of $\mathrm{O} 2$ emissions for all fuels. [11-21]. 


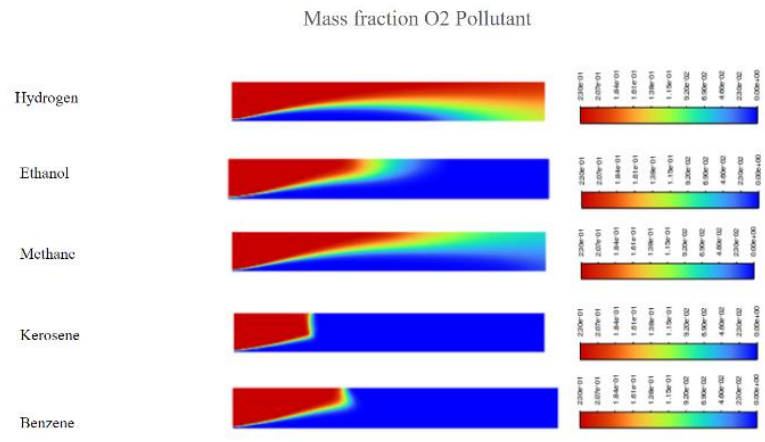

(a)

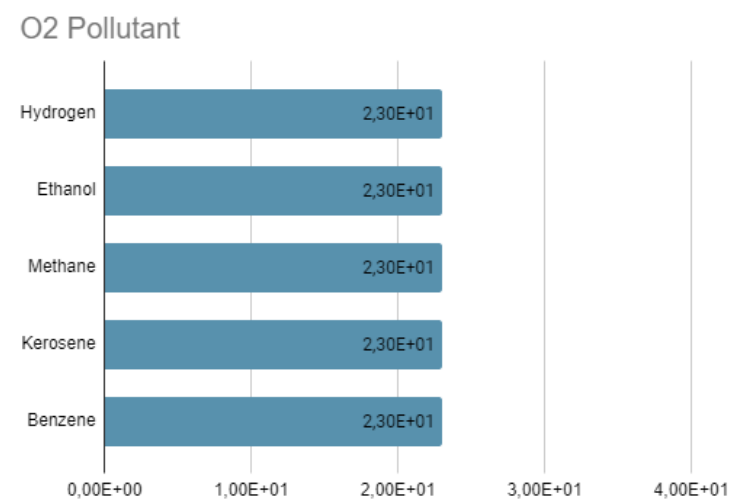

(b)

Figure 7. (a) $\mathrm{O} 2$ Pollutant Mass Fraction distribution contours for combustion chamber. (b)Levels of $\mathrm{O} 2$ distribution recorded for all fuels

\subsection{Mass fraction of $\mathrm{H} 2 \mathrm{O}$ emission}

The formation of mass fraction $\mathrm{H} 2 \mathrm{O}$ emission was found to be higher for hydrogen while the lowest was registered by benzene. We determine that the formation of $\mathrm{H} 2 \mathrm{O}$ is a strong indicator of the extent of combustion. The formation of mass fraction $\mathrm{H} 2 \mathrm{O}$ emissions is highest at the outlet for all the fuels as indicated per the $\mathrm{H} 2 \mathrm{O}$ contours.

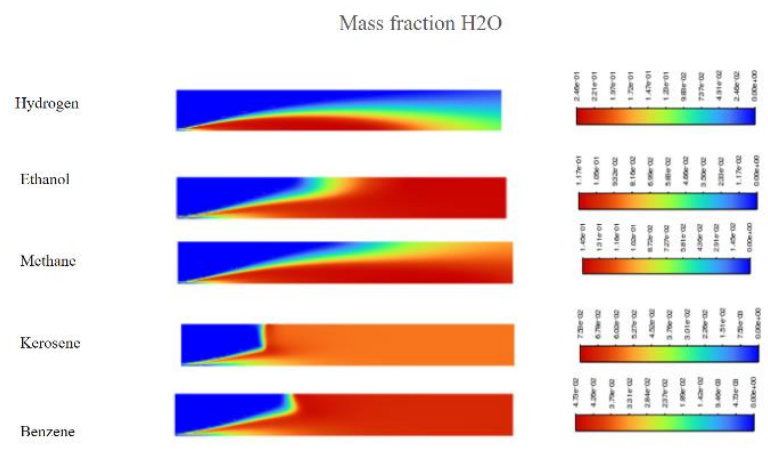

(a) 


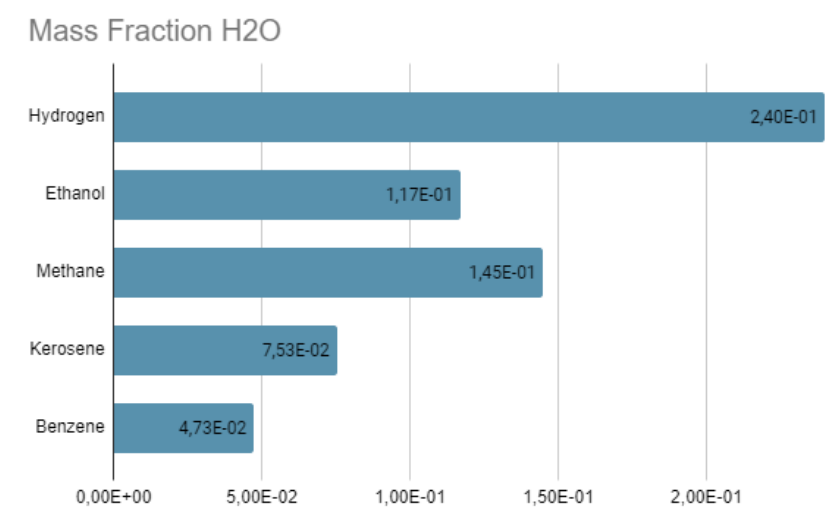

(b)

Figure 8. (a) H2O Mass Fraction distribution contours for combustion chamber. (b)Levels of $\mathrm{H} 2 \mathrm{O}$ distribution recorded for all fuels

\section{CONCLUSIONS}

We analyzed the combustion of Hydrogen, Ethanol, Methane, Kerosene and Benzene using a spice transport mode in order to determine the viability of alternative combustibles to replace current Jet fuels in commercial aviation by looking at the emission of each proposed fuel. From the computational analysis we were able to determine that the performance of Hydrogen-Air is better than other fuels, in regards to pollutant emissions. We determined that hydrogen is the only fuel that does not emit CO2. Hydrogen is also the only fuel which avoids all emissions except water vapor and nitrous oxide.

\section{REFERENCES}

[1]Abay K, Colak U, Yüksek L. Computational fluid dynamics analysis of flow and combustion. J Therm Eng 2018;4:1878-1895. [CrossRef]

[2]Ascensão Costa Morão, I. I., \& Ribeiro Proença Brojo, F. M. (2020). Prediction of Pollutants Emissions in a CFM56-3 Combustor, Using Large Eddy Simulation. KnE Engineering, 5(6), 341-355. https://doi.org/10.18502/keg.v5i6.705

[3]Azar, C., Lindgren, K., \& Andersson, B. A. (1970, January 1). [PDF] hydrogen or methanol in the transportation sector: Semantic scholar. undefined. Retrieved from https://www.semanticscholar.org/paper/Hydrogen-or-methanol-in-the-transportationsector-Azar-Lindgren/eade4a67af57fdd84e186fbfd5b024e745ecf452

[4]Binder, Sergi Gimenez. "Impact of Covid-19 Crisis on Spanish Aviation Industry." Lexology. Augusta Abogados. https://www.lexology.com/commentary/aviation/spain/augusta-abogados/impact-of-covid-19-crisis-on-spanish-aviation-industry. 
[5]"Economic Impacts of Covid-19 on Civil Aviation ." Economic Impacts of COVID-19 on Civil Aviation. https://www.icao.int/sustainability/Pages/Economic-Impacts-ofCOVID-19.aspx.

[6]Flying-V. TU Delft. (n.d.). Retrieved February 3, 2022, from https://www.tudelft.nl/en/ae/flying-v

[7]Gül MZ, Köten H, Yılmaz M, Savcı LH. Advanced numerical and experimental studies on CI engine emissions. J Therm Eng 2018;4:2234-2247.

[8]Iata. "Spain's Aviation Sector Must Have a Roadmap for Restart." IATA. Accessed February 4, 2022. https://www.iata.org/en/pressroom/pr/2021-03-16-01/.

[9]Kieckhäfer K, Quante G, Müller C, Spengler TS, Lossau M, Jonas W. Simulation-Based Analysis of the Potential of Alternative Fuels towards Reducing CO2 Emissions from Aviation. Energies. 2018; 11(1):186. https://doi.org/10.3390/en11010186

[10]Koten H. Performance analysis of a diesel engine within a multi. J Therm Eng 2018;4:2075-2082.

[11]Koten H. Hydrogen effects on the diesel engine performance and emissions. Int J Hydrog Energy 2019;43:10511-10519.

[21]Kurien C, Srivastava AK. Review on post-treatment emission control technique by application of diesel oxidation catalysis and diesel particulate. J Therm Eng, 2019;5:108118.

[13]L La Moncloa. “Estado De Alarma.” https://www.lamoncloa.gob.es/covid-19/Paginas/estado-de-alarma.aspx.

[14] Lefebvre A.H., and Ballal D. R., Gas turbine combustion, pp. 9, 359, 360, CRC Press, Boca Raton, United States Of America, 2010 
[15]Masiol, M. and Harrison, R. M,“Aircraft engine exhaust emissions and other airport related contributions to ambient air pollution: A review," Atmospheric Environment, Vol. 95 (May 2014), pp. 409-455.

[16]N. De Nevers, Air pollution control engineering, Boston, McGraw-Hill, ISBN 0$07-039367-2,200$

[17]Muhammed, E. Gas Turbine Fuels. https://prezi.com/xstmwvtocpxn/gas-turbinefuels/ $(30 / 7 / 2019)$

[18]Oliveira, J.,CFD Analysis of the Combustion of Bio-Derived Fuels in the CFM56-3 Combustor,Master's Thesis, Universidade da Beira Interior, Covilhã,Portugal, 2016.

[19]Oztürk U, Hazar H, Yllmaz F. Comparative performance and emission characteristics of peanut seed oil methyl ester (PSME) on a thermal isolated diesel engine. Energy 2019;167:260-268. [CrossRef]

[20]Rajak U, Nashine P, Verma TN. Effect of spirulina microalgae biodiesel enriched with diesel fuel on performance and emission characteristics of $\mathrm{CI}$ engine. J Therm Eng 2020;268:117305. [CrossRef]

[21]Rajak U, Nashine P, Verma TN. Effect of fuel injection pressure in a diesel engine using microalgae-diesel Emulsion. Int J Eng Adv Technol 2019;8:263-271. [CrossRef]

[22]Saha, Indrashis and Mukherjee, Tathagata and Saha, Ankit, CFD Simulation on Combustion and Study of the Effect of Water Content in the Emission of Pollutants (June 26, 2020). Available at SSRN: https://ssrn.com/abstract=3637342 or http://dx.doi.org/10.2139/ssrn.3637342

[23]Shankar S, Astagi HV, Hotti SR, Hebbal O. Effect of exhaust gas recirculation (EGR) on performance, emissions and combustion characteristics of a low heat rejection (LHR) diesel engine using Pongamia biodiesel. J Therm Eng 2016;2:1007-1016.

[24]“Una Velocidad Diferente En Cada Momento Del Vuelo." LATAM Vamos I Web Oficial. https://www.latam.com/vamos/es_ec/articulos/crew/una-velocidad-diferente-encada-momento-del-vuelo/. 
[25]“USC Environmental Health Centers.” Airport pollution linked to acute health effects among people with asthma in Los Angeles - USC Environmental Health Centers. Accessed

\section{BIOGRAPHIES}

Iho López after obtaining her MSc degree has been working in conducting research in application of alternative fuels for commercial aviation. And is working towards the implementation of different technologies to achieve a successful transition to zero emission aviation.

February 4, 2022. https://envhealthcenters.usc.edu/2019/02/ultrafine-particle-pollutionlax.html.

[26]Vezirolu, T., \& Barbir, F. (1992, January 1). Hydrogen: The wonder fuel: Semantic scholar. undefined. from https://www.semanticscholar.org/paper/Hydrogen\%3A-thewonder-fuel-Vezirolu-Barbir/ced716bc251d7e3c732cca0e419d6aaa2457851d

[27]W Whyte, Theodore. "Heathrow Found to Be World's Second Most Polluting Airport in New Report." DeSmog, September 28, 2021.

https://www.desmog.com/2021/09/28/heathrow-found-to-be-worlds-second-most-polluting-airport-in-new-report/.

[28]Xavier Querol, Jordi Massagué, Andrés Alastuey, Teresa Moreno, Gotzon Gangoiti, Enrique Mantilla, José Jaime Duéguez, Miguel Escudero, Eliseo Monfort, Carlos Pérez García-Pando, Hervé Petetin, Oriol Jorba, Víctor Vázquez, Jesús de la Rosa, Alberto Campos, Marta Muñóz, Silvia Monge, María Hervás, Rebeca Javato, María J. Cornide,

Lessons from the COVID-19 air pollution decrease in Spain: Now what?,

Science of The Total Environment, Volume 779,2021,146380, ISSN 0048-9697, https://doi.org/10.1016/j.scitotenv.2021.146380.

[29]Yiğit, S., K. Özay, and T. Veziroglu. "Hydrogen as an Alternative Fuel for Aircrafts." Semantic Scholar, January 1, 1970. https://www.semanticscholar.org/paper/HYDROGEN-AS-AN-ALTERNATIVE-FUEL-FOR-AIRCRAFTS-Yi\%C4\%9Fit\%C3\%96zay/c3e820cc7f0fcdef7ccfa95b81aa0695d3598aee. 